\title{
Nrf2 is a critical regulator of the innate immune response and survival during experimental sepsis
}

\author{
Rajesh K. Thimmulappa, ${ }^{1}$ Hannah Lee, ${ }^{1}$ Tirumalai Rangasamy, ${ }^{1}$ Sekhar P. Reddy, ${ }^{1}$ \\ Masayuki Yamamoto, ${ }^{1,2}$ Thomas W. Kensler, ${ }^{1,3}$ and Shyam Biswal1,3,4 \\ 1Department of Environmental Health Sciences, Bloomberg School of Public Health, Johns Hopkins University, \\ Baltimore, Maryland, USA. ${ }^{2}$ Center for Tsukuba Advanced Research Alliance and Institute of Basic Medical Sciences, \\ University of Tsukuba, Tsukuba, Japan. ${ }^{3}$ Department of Oncology, Sidney Kimmel Comprehensive Cancer Center, and \\ ${ }^{4}$ Division of Pulmonary and Critical Care Medicine, School of Medicine, Johns Hopkins University, Baltimore, Maryland, USA.
}

\begin{abstract}
Host genetic factors that regulate innate immunity determine susceptibility to sepsis. Disruption of nuclear factor-erythroid 2-related factor $2(\mathrm{Nrf2})$, a basic leucine zipper transcription factor that regulates redox balance and stress response, dramatically increased the mortality of mice in response to endotoxin- and cecal ligation and puncture-induced septic shock. LPS as well as TNF- $\alpha$ stimulus resulted in greater lung inflammation in Nrf2-deficient mice. Temporal analysis of pulmonary global gene expression after LPS challenge revealed augmented expression of large numbers of proinflammatory genes associated with the innate immune response at as early as $\mathbf{3 0}$ minutes in lungs of $\mathrm{Nrf2}$-deficient mice, indicating severe immune dysregulation. The expression profile indicated that $\mathrm{Nrf2}$ has a global influence on both $\mathrm{MyD88}$-dependent and -independent signaling. $\mathrm{Nrf2}$ deficient mouse embryonic fibroblasts showed greater activation of NF- $\kappa B$ and interferon regulatory factor 3 in response to LPS and polyinosinic-polycytidylic acid [poly(I:C)] stimulus, corroborating the effect of $\mathrm{Nrf} 2$ on MyD88-dependent and -independent signaling. Nrf2's regulation of cellular glutathione and other antioxidants is critical for optimal NF- $\kappa B$ activation in response to LPS and TNF- $\alpha$. Our study reveals $N r f 2$ as a novel modifier gene of sepsis that determines survival by mounting an appropriate innate immune response.
\end{abstract}

\section{Introduction}

The innate immune system is the first line of host defense for sensing and eliminating invading microorganisms (1). During pathogenic infection, host inflammatory processes mediate the destruction of the causal agent; however, if inflammation is dysregulated, it can lead to persistent tissue damage, various pathophysiological disorders, or death (2). Sepsis is characterized by dysregulation of inflammation following primarily bacterial infection. The incidence of sepsis in the United States ranges from 400,000 to 750,000 cases per year. Mortality due to sepsis is around 30\% and increases with age from $10 \%$ in children to $40 \%$ in the elderly; mortality is $50 \%$ or greater in patients with the more severe syndrome, septic shock $(1,3)$. The specific reasons for uncontrolled inflammation and death in some septic patients are not clear (1).

The magnitude of the inflammatory response is vital for resolving sepsis because insufficient responses arising from immunodeficiency can propagate further infection whereas an excessive inflammatory response is autodestructive and may lead to microcirculatory dysfunction, causing tissue damage, myocardial injury, acute respiratory failure, multiple organ fail-

Nonstandard abbreviations used: ATP, adenosine 5 '-triphosphate; BAL, bronchoalveolar lavage; CLP, cecal ligation and puncture; GCLC, glutamate cysteine ligase catalytic subunit; GPX2, glutathione peroxidase 2; GSH, glutathione; GSSG, oxidized glutathione; IKK, IKB kinase; IRF3, interferon regulatory factor 3; ISRE, interferon-stimulated response element; $\mathrm{MEF}$, mouse embryonic fibroblast; NAC, N-acetyl cysteine; Nrf2, nuclear factor-erythroid 2-related factor 2; p, phosphorylated; poly(I:C), polyinosinic-polycytidylic acid; RelA, v-rel reticuloendotheliosis viral oncogene homolog $\mathrm{A}$.

Conflict of interest: The authors have declared that no conflict of interest exists. Citation for this article: J. Clin. Invest. 116:984-995 (2006). doi:10.1172/JCI25790. ure, and ultimately death (1). Host factors that regulate innate immunity may protect against dysregulated inflammation and help to effectively control inflammation. Few host factors that are vital for controlling inflammation are known, and identification of novel factors can help us to better understand the innate immune response. Various studies have reported associations of innate immunity to variants in genes encoding proteins such as TLRs, TNF- $\alpha$, LPS-binding protein, CD14, and bactericidal/permeability-increasing protein $(1,4)$.

Nuclear factor-erythroid 2-related factor 2 (Nrf2), a basic leucine zipper redox-sensitive transcription factor, is a pleiotropic protein that regulates the basal and inducible expression of a battery of antioxidant and other cytoprotective genes by binding to a cis-acting enhancer sequence known as the antioxidant response element (5-8). Under normal conditions, nuclear levels of Nrf2 are low; however, under stress such as oxidative stimuli, nuclear accumulation of $\mathrm{Nrf} 2$ increases, resulting in enhanced transcriptional activation of its targets, which in turn confers protection against various environmental stresses (7-12). Here, we report that $\mathrm{Nrf2}$ is a novel regulator of the innate immune response that dramatically improves survival during experimental sepsis by protecting against dysregulated inflammation.

\section{Results}

Disruption of Nrf2 causes drastic increase in lethality during LPS and cecal ligation and puncture-induced septic shock. First, we examined the role of $\mathrm{Nrf2}$ on the survival of wild-type $\left(\mathrm{Nrf2} 2^{++}\right)$and $\mathrm{Nrf2}$-deficient $\left(\mathrm{Nrf2^{-/- }}\right)$ mice during an endotoxic shock. $\mathrm{Nrf2^{+/+ }}$ and $\mathrm{Nrf2^{-/- }}$ mice were treated i.p. with a lethal dose of LPS ( 0.75 and $1.5 \mathrm{mg} / \mathrm{mouse})$, and survival was monitored for 5 days. The lower dose resulted in 

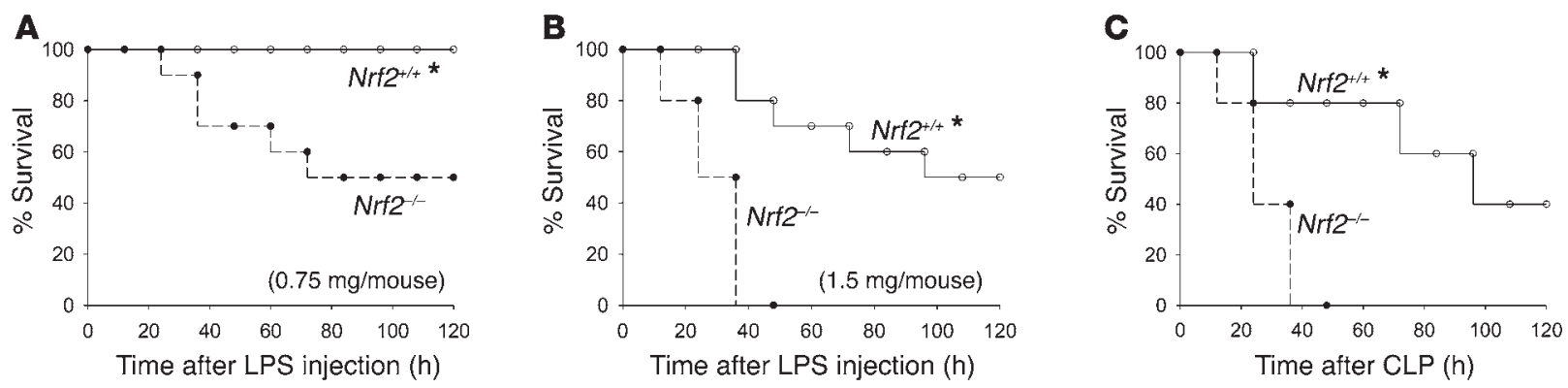

Figure 1

$\mathrm{Nrf2}^{-1-}$ mice were more sensitive to LPS and septic peritonitis-induced septic shock. (A and B) Mortality after LPS administration. Age-matched male $\mathrm{Nrf2}^{+/+}(n=10)$ and $\mathrm{Nrf2}^{-/-}$mice $(n=10)$ were injected i.p. with LPS $(0.75$ and $1.5 \mathrm{mg}$ per mouse). (C) Acute septic peritonitis was induced by CLP. CLP and sham operations were performed as described in Methods on age-matched male $\mathrm{Nrf2} 2^{+/+}(n=10)$ and $\mathrm{Nrf2}-/-$ mice $(n=10)$. Mortality was assessed every 12 hours for 5 days. ${ }^{*} \mathrm{Nrf2}^{+/+}$mice showed improved survival compared with $\mathrm{Nrf2}{ }^{-/-}$mice. $P<0.05$.

the death of $50 \%$ of the $\mathrm{Nrf2^{-/- }}$ mice but none of the $\mathrm{Nrf2^{+/+ }}$ mice (Figure 1A). At the higher dose, $100 \%$ of the $N r f 2^{-1-}$ mice died within 48 hours whereas only $50 \%$ of the $N r f 2^{+/+}$mice died by day 5 (Figure 1B). Next, we investigated the role of Nrf2 on survival in a clinically relevant model of septic shock induced by cecal ligation and puncture (CLP). By 48 hours after CLP, all Nrf2 $2^{-/}$mice died while only $20 \%$ of wild-type littermates died. After 5 days, $40 \%$ of wild-type mice still survived (Figure 1C). No death was observed in sham-operated mice of both genotypes.

LPS elicits greater pulmonary inflammation in Nrf2-deficient mice. Because it is clear that Nrf2 is critical for survival during lethal septic shock, the role of this transcription factor in regulating nonlethal inflammatory stimulus was investigated. Lungs were examined after systemic (i.p. injection of $60 \mu \mathrm{g} / \mathrm{mouse}$ ) or local (intratracheal instillation of $10 \mu \mathrm{g} /$ mouse) administration of LPS. For both modes of LPS administration, the inflammatory response was greater in the lungs of $\mathrm{Nrf2}^{-/-}$mice than in their wild-type littermates. The influx of inflammatory cells (neutrophils and macrophages) was greater in the lungs of $\mathrm{Nrf2}^{-1-}$ mice at both 6 and 24 hours after LPS challenge by either route. After i.p. administration of LPS, macrophages were the predominant cell type in bronchoalveolar lavage (BAL) fluid although both macrophages and neutrophils showed temporal increase in numbers (Figure 2, $A$ and B). In contrast, intratracheal instillation attracted predominantly neutrophils (constituting as much as $80 \%$ of the total inflammatory cell population) in BAL fluid (Figure 2C), a finding similar to that of other investigators (13). Consistent with the BAL fluid analysis, histopathology showed a greater recruitment


Figure 2

Nonlethal dose of LPS induced greater lung inflammation in Nrf2-deficient lungs. (A and B) BAL fluid analysis of $\mathrm{Nrf2} 2^{-/-}$and $\mathrm{Nrf2}+/+$ mice after 6 and 24 hours of i.p. injection of LPS $\left(60 \mu \mathrm{g}\right.$ per mouse). (C) BAL fluid analysis of $N r f 2^{-/-}$and Nrf2+/+ mice after 6 hours and 24 hours of LPS instillation (10 $\mu \mathrm{g}$ per mouse). (D) Histopathological analysis of lungs by H\&E staining 24 hours after instillation of LPS. Arrows indicate accumulation of inflammatory cells in the alveolar spaces. Magnification, $\times 20$. (E) Immunohistology of lungs of both genotypes using anti-mouse neutrophil antibody 24 hours after LPS instillation. Sections were counterstained with hematoxylin. Arrows indicate neutrophils. Magnification, $\times 40$. (F) Myeloperoxidase (MPO) activity in lung homogenates of both genotypes 6 and 24 hours after LPS instillation. (G) Pulmonary edema was assessed by the ratio of wet to dry lung weight 24 hours after LPS instillation. Data are presented as mean \pm SEM; $n=5$. *Differs from vehicle

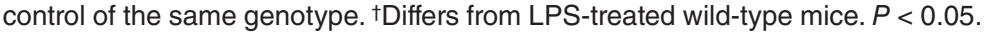



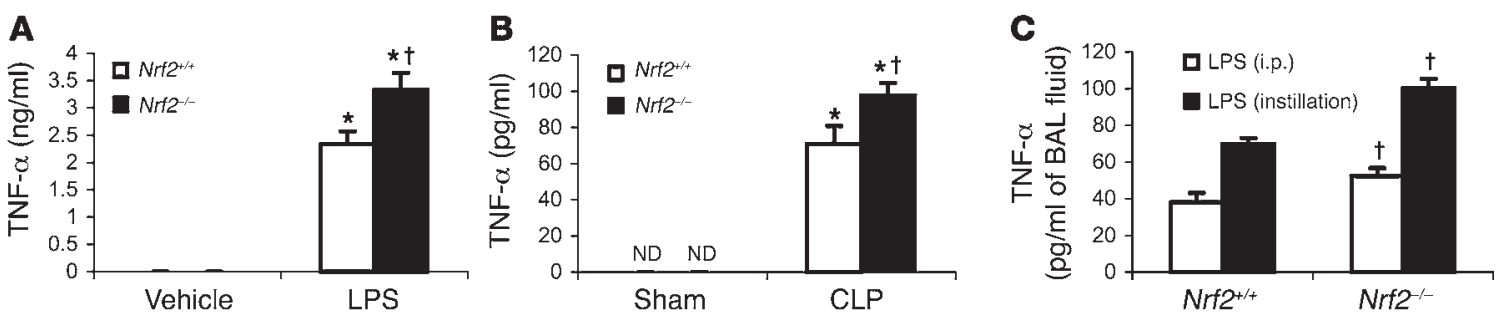

\section{Figure 3}

LPS and CLP induce greater secretion of TNF- $\alpha$ in Nrf2-deficient mice. (A) Serum concentration of TNF- $\alpha$ in Nrf2+/+ and Nrf2-/- mice 1.5 hours after LPS injection (1.5 mg per mouse). (B) Serum concentration of TNF- $\alpha$ in Nrf2+/+ and Nrf2 ${ }^{-/-}$mice 6 hours after CLP. (C) TNF- $\alpha$ levels in BAL fluid at 2 hours after LPS delivery by i.p. injection (60 $\mu \mathrm{g}$ per mouse) and/or intratracheal instillation (10 $\mu \mathrm{g}$ per mouse). TNF- $\alpha$ in the BAL fluid of vehicle-treated mice was not detectable. Data are presented as mean \pm SEM. ${ }^{*}$ Differs from vehicle control of the same genotype. ${ }^{\mathrm{D}} \mathrm{Differs}$ from LPS-treated wild-type mice. $P<0.05$. ND, not detected.

of inflammatory cells in perivascular, peribronchial, and alveolar spaces of $\mathrm{Nrf2} 2^{-/-}$mice 24 hours after LPS treatment (Figure 2D). Immunohistochemical examination of LPS-instilled lungs with anti-neutrophil antibody also confirmed a greater number of neutrophils in the lungs of $\mathrm{Nrf2}^{-/-}$mice (Figure $2 \mathrm{E}$ ), which was further evident from myeloperoxidase activity in these lungs (Figure $2 \mathrm{~F}$ ). As a marker of lung injury, pulmonary edema was observed to be markedly higher in $N r f 2^{-/-}$mice 24 hours after LPS instillation (Figure 2G). A similar pattern of lung pathological injury was induced by systemic delivery of LPS (data not shown). Taken together, these results show that disruption of the Nrf2 gene augments the innate immune response to bacterial endotoxin.

LPS and CLP induced greater secretion of TNF- $\alpha$ in Nrf2-deficient mice. Since TNF- $\alpha$ is one of the early proinflammatory cytokines that is elevated during LPS- and CLP-induced inflammation, serum concentrations of TNF- $\alpha$ were measured by ELISA. After 1.5 hours of LPS challenge ( $1.5 \mathrm{mg} /$ mouse), serum TNF- $\alpha$ was significantly higher in $\mathrm{Nrf2}^{-/-}$mice compared with $\mathrm{Nrf2}^{+/+}$(Figure 3A). Similarly, after 6 hours of CLP, serum levels of TNF- $\alpha$ were greater in $\mathrm{Nrf2}^{-/-}$compared with $\mathrm{Nrf2} 2^{+/+}$mice (Figure 3B). Furthermore,
TNF- $\alpha$ concentrations in BAL fluid were also greater 2 hours after nonlethal LPS challenge (i.p. and intratracheal instillation) in $N r f 2^{-/-}$mice compared with wild-type mice (Figure 3C). Next, we measured the concentrations of TNF receptors, TNFRI (p55) and TNFRII (p75), in Nrf2 $2^{+/+}$and $\mathrm{Nrf2}^{-{ }^{--}}$mice after a lethal dose of LPS. While there was no difference in the constitutive serum levels of p55 and p75, after 6 hours of LPS treatment, the serum concentrations of both receptors were increased significantly. However there were no significant differences in the TNF receptors between the $\mathrm{Nrf2} 2^{-/-}$and $\mathrm{Nrf2^{+/+ }}$ mice (Supplemental Figure 1; supplemental material available online with this article; doi:10.1172/ JCI25790DS1) after LPS challenge.

Temporal global changes in gene expression reflect the impact of Nrf2 on the innate immune response. Moderate increase in TNF- $\alpha$ production alone cannot explain the markedly higher CLP- and LPS- induced mortality as well as LPS-induced lung inflammation in $\mathrm{Nrf2^{-/- }}$ mice (14). To systematically understand the role of Nrf2 during LPSinduced inflammation, the global gene expression profiles were examined in lungs of $\mathrm{Nrf2}^{-/-}$and $\mathrm{Nrf2}^{+/+}$mice over time in response to a nonlethal LPS stimulus. After i.p. injection of LPS, microarray

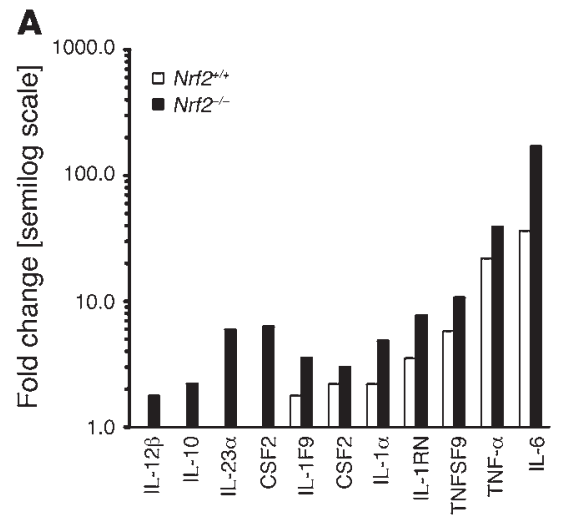

Cytokines
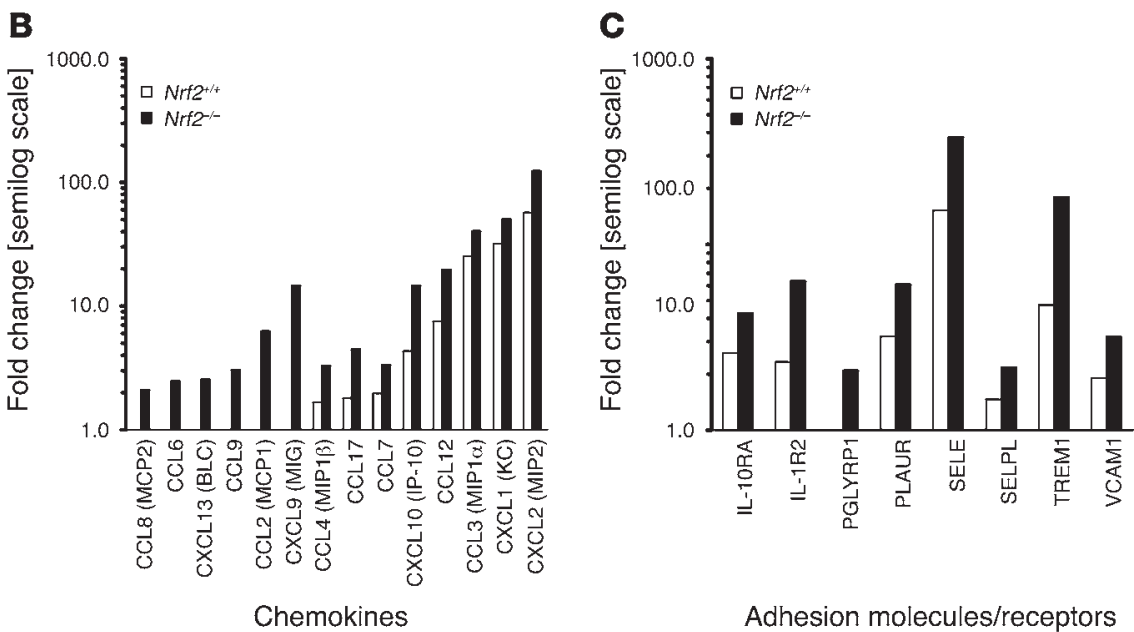

Adhesion molecules/receptors

Figure 4

Greater expression of proinflammatory genes associated with the innate immune response in the lungs of Nrf2-deficient mice. (A-C) Expression of cytokines (A), chemokines (B), and adhesion molecules/receptors (C) 30 minutes after nonlethal i.p. injection of LPS (60 $\mu \mathrm{g}$ per mouse) in Nrf2-deficient and wild-type mice. Gene expression data were obtained from microarray analysis. Data are represented as mean fold change obtained from comparing LPS-challenged to vehicle-treated lungs of the same genotype on a semilog scale. All the represented fold change values of LPS-treated lungs of $\mathrm{Nrf2}^{-/-}$mice are significant compared with wild-type mice at $P<0.05$. 



Figure 5

TNF- $\alpha$ stimulus induced greater lung inflammation in Nrf2-deficient mice. (A) BAL fluid analysis at 6 hours after i.p. injection of TNF- $\alpha$ (10 $\mu g / m o u s e)$. (B) Histopathological analysis of lungs of $\mathrm{Nrf2}^{+/+}$and $\mathrm{Nrf}^{-/-}$mice by H\&E staining 24 hours after i.p. injection of TNF- $\alpha$ (10 $\mu \mathrm{g} / \mathrm{mouse}$ ). Vehicletreated lungs are not shown. Magnification, $\times 20$. (C) Gene expression analysis of TNF- $\alpha, \mathrm{IL}-1 \beta$, and IL-6 by real-time PCR in the lungs of Nrf2-and $\mathrm{Nrf2}^{+/+}$mice 30 minutes after TNF- $\alpha$ challenge. Data are presented as mean \pm SEM. ${ }^{*}$ Differs from vehicle control of the same genotype. tDiffers from LPS-treated wild-type mice. $P<0.05$.

analyses of lungs were performed at 30 minutes, 1 hour, 6 hours, 12 hours, and 24 hours. Nrf2 deficiency resulted in the enhanced expression of several clusters of genes associated with the innate immune response, even at as early as 30 minutes (Figure 4). These included specific cytokines, chemokines, and cell surface adhesion molecules and receptors, among others. Differences between genotypes in expression of most of the proinflammatory genes in the lungs of mice were significant at the early time points (30 minutes and 1 hour) following LPS challenge. At later time points, with few exceptions, there was no significant difference in expression of proinflammatory genes between the genotypes. Henceforth, unless otherwise stated, a more detailed presentation of the gene expression profile obtained at 30 minutes is provided while the remaining data for the time course is presented as supplemental data. The microarray results indicate that $\mathrm{Nrf2}$ functionality is indispensable for controlling the early surge of a large number of proinflammatory genes associated with the innate immune response.

Cytokines and chemokines. At 30 minutes after LPS challenge, gene expression for cytokines such as TNF- $\alpha$, TNFSF9, IL-1 $\alpha, I L-6, I L 1 F 9$, $I L-10, I L-12 \beta, I L-23 p 19, C S F 1$, and CSF2 was significantly higher in lungs of $\mathrm{Nrf2}^{-/-}$compared with $\mathrm{Nrf2} 2^{+/+}$mice. Among all cytokines, the expression of IL- 6 was highest. Members of C-C family (CCL12

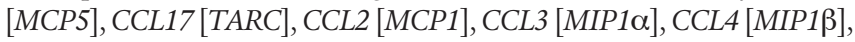
and CCL6 and CCL8 [MCP2]) and C-X-C chemokines (MIP2, MIG, KC, $I T A C, I P-10$, and CXCL13) were greatly upregulated in LPS-challenged $\mathrm{Nrf2} 2^{-/}$lungs relative to $\mathrm{Nrf2^{+/+ }}$ (Figure 4 and Supplemental Table 1).

Cell surface adhesion molecules and receptors. Disruption of Nrf2 had no effect on the expression of the LPS signaling receptor, $T L R 4$, after LPS challenge. CD14 transcript was markedly higher in Nrf2-/- lungs. Expression of several adhesion molecules, such as PGLYRP1 (a member of the peptidoglycan recognition protein family; ref. 15), TREM-1, SELE, SELP, VCAM1, and members of the C-type lectin family (CLEC4D, CLEC4E) were highly upregulated in Nrf2-/- lungs (Supplemental Table 2). C5AR, which mediates C5A response and augments sepsis (16), was upregulated to a greater extent in $\mathrm{Nrf2}^{-\gamma-}$ mice (Supplemental Table 2). Among the cell surface adhesion molecules, TREM1 and CD14 were highly upregulated in $\mathrm{Nrf2}^{-/-}$lungs.

Regulators of cytokine signaling and transcription. Transcripts of SOCS3, which are involved in downregulating cytokine signaling, were induced to a greater extent in $\mathrm{Nrf2^{-/ }}$ lungs at early time points (Supplemental Table 1). Transcription factors belonging to the NF-KB family (C-RELC, RELB, NFKBIZ, NFKB2, NFKBIE), the interferon family (IRF5, IRF1, IFI202B, IFI204, IRF1), and the early growth response family (EGR2, EGR3) as well as STAT4, which collectively regulate different inflammatory cascade pathways, were expressed to higher levels in $N r f 2^{-/-}$lungs when compared with wild-type mice (Supplemental Table 3).

Immunoglobulin and MHC. Transcripts of many members of the immunoglobulin family (IGHG, IGH-VJ558, IGH-4, IGH-6, IGJ, IGK-V21, IGk-V32, IGK-V8, IGL-V1, IGSF6, and IGM) as well as the MHC class II family (H2-AA, H2-AB1, H2-EA, H2-DMA, $\mathrm{H} 2$-DMB1, and $\mathrm{H} 2$-DMB2) were selectively upregulated in the lungs of $\mathrm{Nrf2}^{-/-}$mice at 30 minutes (Supplemental Table 4), indicating severe immune dysfunction.

Acute phase proteins, heat shock proteins, and other inflammationmodulating molecules and enzymes. Many genes that encode for acute phase proteins such as proteinase inhibitors (SERPINA3M, 

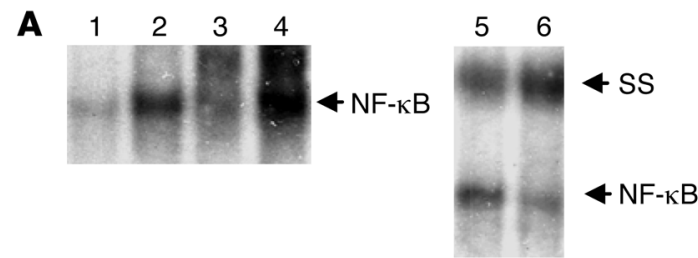

B

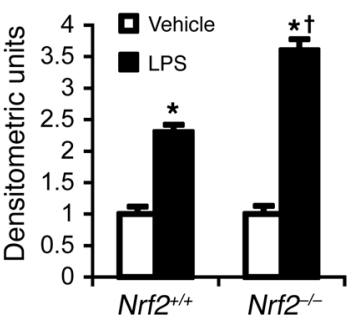

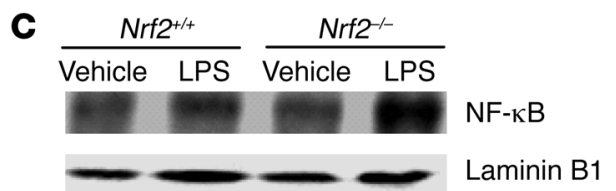

D

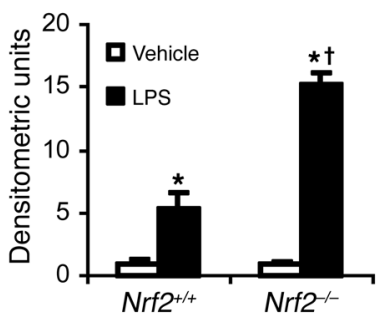

\section{Figure 6}

LPS induced greater NF- $\mathrm{KB}$ activation in lungs of Nrf2-deficient mice. (A) Lung nuclear extracts from $\mathrm{Nrf2}^{-/-}$and $\mathrm{Nrf2} 2^{+/+}$mice were assayed for

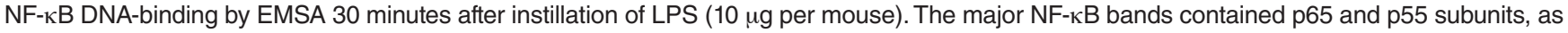

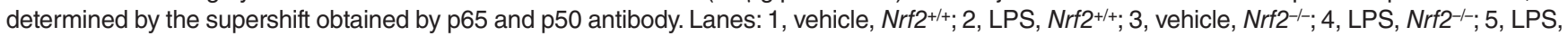
$\mathrm{Nrf2}^{+/+}$with p65 antibody, 6, LPS, Nrf2+/+ with p50 antibody. SS, supershift. (B) Quantification of NF-kB DNA-binding was performed by densitometric analysis. All values are mean \pm SEM obtained from 3 animals per treatment group and are represented as relative to respective vehicle control. (C) Nuclear accumulation of $\mathrm{p} 65$ by Western blot in the nuclear extracts derived from lungs of $\mathrm{Nrf2}^{+/+}$and $\mathrm{Nrf2} 2^{-/}$mice 30 minutes after instillation of LPS (10 $\mu \mathrm{g} / \mathrm{mouse}$ ). Lamin B1 was used as loading control. (D) Densitometric analysis of Western blot of RelA relative to wild-type vehicle control. All values are mean $\pm \mathrm{SEM} ; n=3$. ${ }^{*}$ Differs from vehicle control of the same genotype. ${ }^{\dagger}$ Differs from LPS-treated wild-type mice. $P<0.05$.

SERPINB2, and SERPINE1), serum amyloid A (SAA2, SAA3), orsomucoid (ORM1, ORM2), and HSP1A were markedly increased in Nrf2-/- lungs (Supplemental Table 5). Expression levels of $A R G 2$ (an endogenous inhibitor of iNOS that regulates arginine metabolism; ref. 17), INDO (exerts immunosuppressive effects through induction of apoptosis in T cells by regulating tryptophan metabolism; ref. 18), PLEK (regulates phagocytosis activity by macrophages; ref.19), and PFC (regulator of alternative complement system) were all higher in $\mathrm{Nrf2}^{-/-}$lungs at 30 minutes (Supplemental Table 6).

ROS/RNS generators. The expression of NCF1 ( $447 p h o x)$ and NCF4 ( $p 40$ phox), which are members of the NADPH oxidase family involved in generation of reactive oxygen species during phagocytic activity by neutrophils and macrophages, were significantly higher in Nrf2-l- lungs at early stages (until 1 hour; Supplemental Table 6). Expression of NOS2 (iNOS), which is involved in nitric oxide generation, was induced at the 6-hour time point and was greater in the lungs of $\mathrm{Nrf2} 2^{-1-}$ mice (Supplemental Table 6).

Antioxidants. Nrf2 is a key transcription factor for regulating the expression of antioxidative genes. Differential gene expression profiling of vehicle-treated $\mathrm{Nrf2}^{+/+}$and $\mathrm{Nrf2^{-/- }}$ lungs showed constitutively elevated expression of antioxidative genes such as glutathione peroxidase 2 (GPX2), glutamate cysteine ligase catalytic subunit $(G C L C)$, thioredoxin reductase 1 , and members of the glutathione $S$-transferase family in wild-type mice (Supplemental Table 7). Although expression of these genes was not altered significantly in wild-type mice after LPS challenge, at all time points, transcript levels of these antioxidative genes were higher in the lungs of wild-type mice compared with $\mathrm{Nrf2^{-/ }}$ mice.

Validation of microarray data by real-time quantitative PCR. Genes that were selected for validation included chemokines (MCP5, $M C P 1$, and MIP2), cytokines (IL-6, IL-1 $\alpha, T N F-\alpha$, and CSF2), an LPS membrane receptor (CD14), immunoglobulins (IGH-4 and IHSF6), an MHC class II member (H2-EA), and the transcription factor
STAT4. Expression values of these genes obtained from real-time PCR were consistent with the microarray values in terms of magnitude and pattern across all time points (Supplemental Table 8).

TNF- $\alpha$ stimulus induces a greater pulmonary inflammatory response in Nrf2-deficient mice. Microarray and BAL fluid analysis showed greater expression of TNF- $\alpha$ in the lungs of $N r f 2^{-/-}$mice compared with $\mathrm{Nrf2} 2^{+/+}$mice in response to LPS. To characterize the effect of TNF- $\alpha$-mediated inflammation, mice of both genotypes were administered TNF- $\alpha$ (i.p.). Following TNF- $\alpha$ treatment, lungs of $\mathrm{Nrf2^{-/ }}$ mice showed increased infiltration of inflammatory cells as measured by BAL fluid analysis and histopathology (Figure 5, $A$ and $B$ ) when compared with wild-type littermates. Real-time PCR analysis of selected genes (TNF- $\alpha, I L-1 \beta$, and $I L-6)$ in the lungs of mice 30 minutes after TNF- $\alpha$ treatment revealed greater expression in $\mathrm{Nrf2} 2^{-/-}$mice compared with $\mathrm{Nrf2} 2^{+/+}$(Figure 5C). Taken together, as with LPS, treatment with TNF- $\alpha$ induced greater inflammation in $\mathrm{Nrf2^{-/ }}$ lungs.

$N F-\kappa B$ activity is greater in lungs of LPS-treated Nrf2-deficient mice. Because the lungs of $\mathrm{Nrf2}^{-/-}$mice showed greater infiltration of inflammatory cells and higher expression of largely inflammation-associated genes, we assessed NF- $\mathrm{BB}$ activity, which regulates the expression of several genes that are essential for initiating and promoting inflammation (20). At 30 minutes after LPS instillation, NF-кB DNA-binding activity was significantly higher in nuclear extracts from lungs of $\mathrm{Nrf2}^{-/-}$mice than in their wild-type counterparts, suggesting an inhibitory role of $\mathrm{Nrf2}$ on NF- $\kappa \mathrm{B}$ activation (Figure 6, A and B). Western blot analysis confirmed a greater increase in nuclear levels of p 65 , an NF- $\mathrm{B}$ subunit, in the LPS-treated lungs of $\mathrm{Nrf2}^{-/-}$mice than in $\mathrm{Nrf2}^{+/+}$mice (Figure 6, C and D). Similarly, nuclear extracts from the lungs of $\mathrm{Nrf2}^{-/-}$mice showed increased binding of p $65 / \mathrm{v}$-rel reticuloendotheliosis viral oncogene homolog A (p65/RelA) subunits to NF- $\kappa \mathrm{B}-$ binding sequence as measured by ELISA using Mercury TransFactor ELISA kit (Supplemental Figure 3A). A similar trend 
A

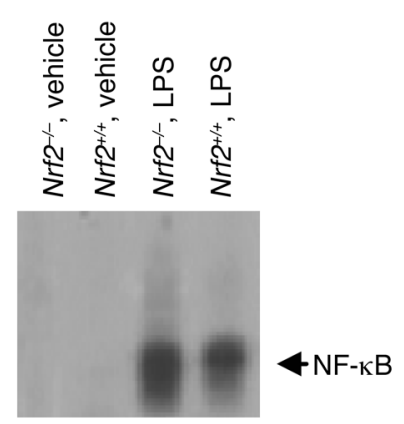

B

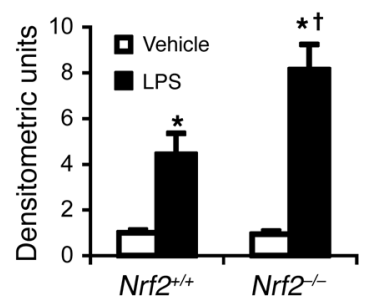

C

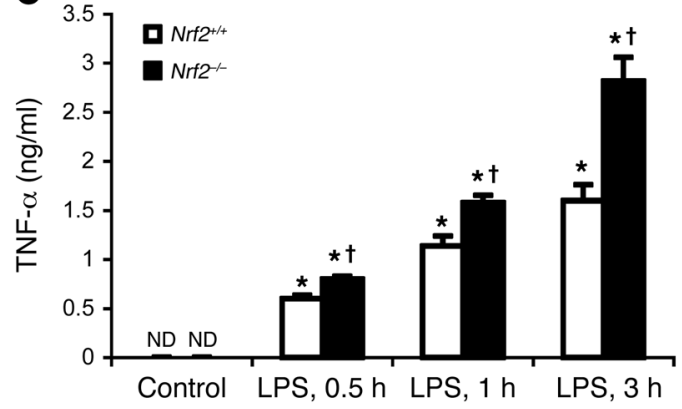

Figure 7

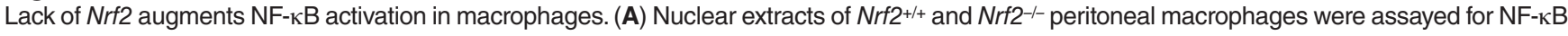
DNA-binding by EMSA 20 minutes after LPS treatment $(1 \mathrm{ng} / \mathrm{ml})$. (B) Densitometric analysis of NF-kB DNA-binding relative to wild-type vehicle control. Values are mean \pm SEM; $n=3$. (C) TNF- $\alpha$ levels in the culture media from $\mathrm{Nrf2}^{+/+}$and $\mathrm{Nrf2}^{-/-}$peritoneal macrophages after 0.5 hours, 1 hours, and 3 hours of LPS treatment $(1 \mathrm{ng} / \mathrm{ml})$. ${ }^{*}$ Differs from vehicle control of the same genotype. ${ }^{\dagger}$ Differs from wild-type treatment group. $P<0.05$.

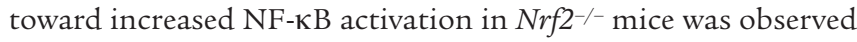
at 30 minutes and 1 hour following i.p. injection of LPS at a nonlethal dose (data not shown).

LPS induces greater NF-KB activity and TNF- $\alpha$ secretion in peritoneal macrophages from Nrf2-deficient mice. Macrophages play a central role in immune dysfunction during endotoxic shock. To examine the effect of Nrf2 deficiency on NF- $\mathrm{KB}$ activation in macrophages, resident peritoneal macrophages were stimulated with LPS. After 20 minutes, the DNA-binding activity of NF- $\kappa B$ was substantially higher in $\mathrm{Nrf2}^{-\gamma^{--}}$macrophages than in the wild-type counterparts as determined by EMSA (Figure 7, A and B). The greater increase in NF- $\kappa \mathrm{B}$ activity in $\mathrm{Nrf2}^{-/-}$macrophages correlated well with the increase in TNF- $\alpha$ levels measured 0.5 hours, 1 hour, and 3 hours after LPS treatment (Figure 7C).

Increased NF- $\kappa B$ activation by LPS or TNF- $\alpha$ in Nrf2-deficient mouse embryonic fibroblasts. To further probe the role of $\mathrm{Nrf} 2$ in regulating NF- $\kappa \mathrm{B}$, mouse embryonic fibroblasts (MEFs) derived from $N r f 2^{-/-}$and $N r f 2^{+/+}$mice were exposed to LPS or TNF- $\alpha$. Both LPS and TNF- $\alpha$ stimulation resulted in enhanced activation of NF- $\kappa \mathrm{B}$ in $\mathrm{Nrf2^{-/- }}$ MEFs compared with $\mathrm{Nrf2} 2^{+/+}$cells as measured by EMSA (Figure 8A). There were 3 - and 5-fold increases in NF-KB activation in $\mathrm{Nrf} 2^{-/-}$MEFs relative to wild-type in response to LPS or TNF- $\alpha$ stimulation, respectively (Figure $8 \mathrm{~B}$ ). The specificity of $\mathrm{NF}-\kappa \mathrm{B}$ binding was assessed by adding an excess of cold mutant NF-кB oligo to the binding reactions. Supershift analysis of nuclear extracts from LPS- and TNF- $\alpha$-treated $N r f 2^{-/-}$MEFs with $\mathrm{p} 65$ and p50 antibodies demonstrated heterodimers of p50 and p65. Nuclear extracts from the Nrf2 $2^{-/-}$MEF cells treated with LPS or TNF- $\alpha$ also demonstrated increased binding of p65/RelA subunits to NF- $\mathrm{KB}$ binding sequence as determined by an ELISA-based method of detecting NF- $\mathrm{B}$ DNA-binding activity using Mercury TransFactor ELISA kit (Supplemental Figure 3B). NF-кB-mediated luciferase reporter activity was also greater in $\mathrm{Nrf2^{-/- }} \mathrm{MEFs}$ than in $\mathrm{Nrf2}^{+/+}$MEFs in response to LPS or TNF- $\alpha$ (Figure 8C). In general, the $\mathrm{Nrf2}^{-/-}$MEFs showed greater NF- $\mathrm{\kappa B}$ activation in response to TNF- $\alpha$ compared with LPS stimulation.

$N r f 2$ regulates $N F-\kappa B$ activation by modulating $I \kappa B-\alpha$ degradation. To understand the mechanism of augmented NF- $\kappa B$ activation in

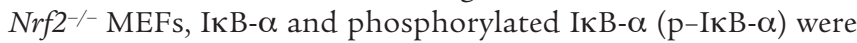
measured in the whole cell extracts of $\mathrm{Nrf2}^{-{ }^{-}}$and $\mathrm{Nrf2^{+/+ }}$ MEFs after treatment with LPS or TNF- $\alpha$. In response to LPS or TNF- $\alpha$,
IкB- $\alpha$ degradation was significantly higher in Nrf2-/- MEFs compared with wild-type cells (Figure 8, D and E). TNF- $\alpha$ stimulus induced greater phosphorylation of IкB- $\alpha$ while LPS induced moderate but statistically significant increases in phosphorylation of IкB- $\alpha$ in Nrf2-/- MEFs compared with $\mathrm{Nrf2}^{+/+}$MEFs (Figure 8, $\mathrm{D}$ and $\mathrm{F}$ ). Furthermore, activity of IкB kinase (IKK) kinase, which regulates phosphorylation of IKB- $\alpha$, was also greater in $\mathrm{Nrf2}^{-/-}$ MEFs in response to LPS or TNF- $\alpha$ (Figure 8, G and H).

Nrf2 affects both MyD88-dependent and MyD88-independent signaling. Microarray gene expression analysis after LPS challenge revealed that, in addition to NF- $\mathrm{KB}$-regulated genes, several interferon regulatory factor 3-regulated (IRF3-regulated) genes (such as IP-10, MIG, ITAC, and ISG54; Supplemental Table 9) were expressed to a greater magnitude in the lungs of $\mathrm{Nrf2}^{-/-}$mice. LPS via TLR4 can activate MyD88-dependent signaling leading to NF- $\mathrm{\kappa B}$ activation as well as MyD88-independent signaling (TRIF/IRF3), resulting in IRF3 activation (21). As shown in Figure 8C, Nrf2 deficiency greatly upregulates NF- $\kappa \mathrm{B}-$ mediated luciferase activity in MEFs in response to LPS, suggesting the effect on MyD88-dependent signaling. In order to understand the influence of Nrf2 deficiency on MyD88-independent signaling, MEFs of both genotypes were transfected with a luciferase reporter vector containing interferon-stimulated response element (ISRE) and treated with LPS or polyinosinic-polycytidylic acid [poly(I:C)]. LPS elicited greater IRF3-mediated luciferase reporter activity in Nrf2 $2^{-/}$MEFs compared with $\mathrm{Nrf2^{+/+ }}$ MEFs (Figure 9). Similarly, in response to poly(I:C), which acts specifically via MyD88-independent signaling (22), IRF3-mediated reporter activity was significantly higher in Nrf2 $2^{--}$MEFs (Figure 9).

Glutathione levels are lower in lungs and MEFs of Nrf2-deficient mice. $\mathrm{Nrf} 2$ is a regulator of a battery of cellular antioxidants, including the glutathione-synthesizing (GSH-synthesizing) enzyme, glutamate cysteine ligase. Constitutive expression of GCLC was significantly lower in the lungs as well as MEFs of $\mathrm{Nrf2}^{-{ }^{--}}$mice compared with $N r f 2^{+/+}$mice (Figure 10A). This difference in expression is reflected in significantly lower endogenous levels of GSH in the MEFs of $\mathrm{Nrf2^{-/- }}$ mice than in $\mathrm{Nrf2} 2^{+/+}$mice (Figure 10D). In response to LPS stimulus, there was a significant decrease in the levels of GSH in MEFs of both genotypes at 1 hour (Figure 10D). In contrast, after 24 hours of LPS treatment, a greater increase in GSH was observed in the lungs of $\mathrm{Nrf2}^{+/+}$mice compared with $\mathrm{Nrf2}^{-/_{-}}$(Figure 10B). 
A

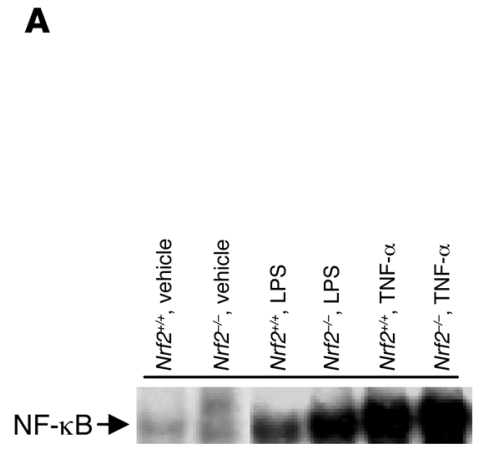

C

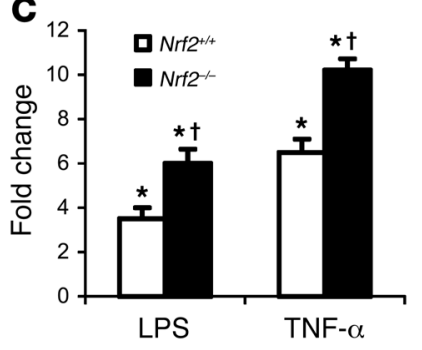

$\mathbf{E}$

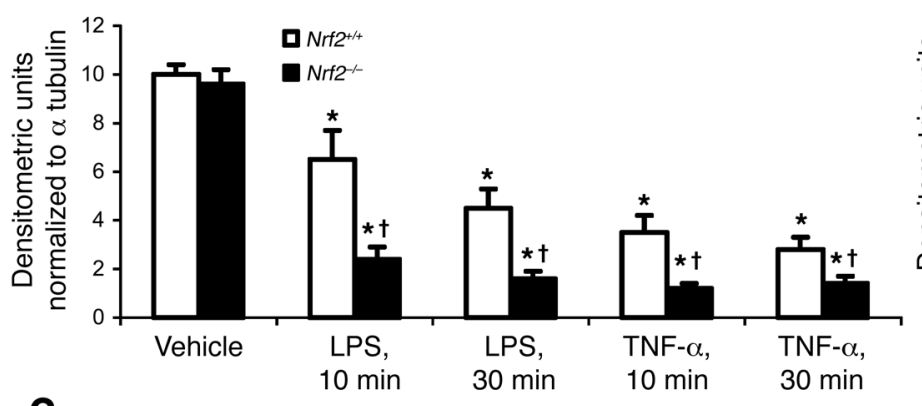

G

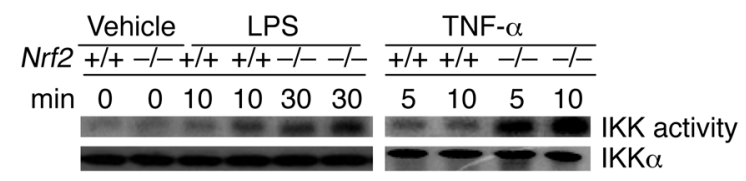
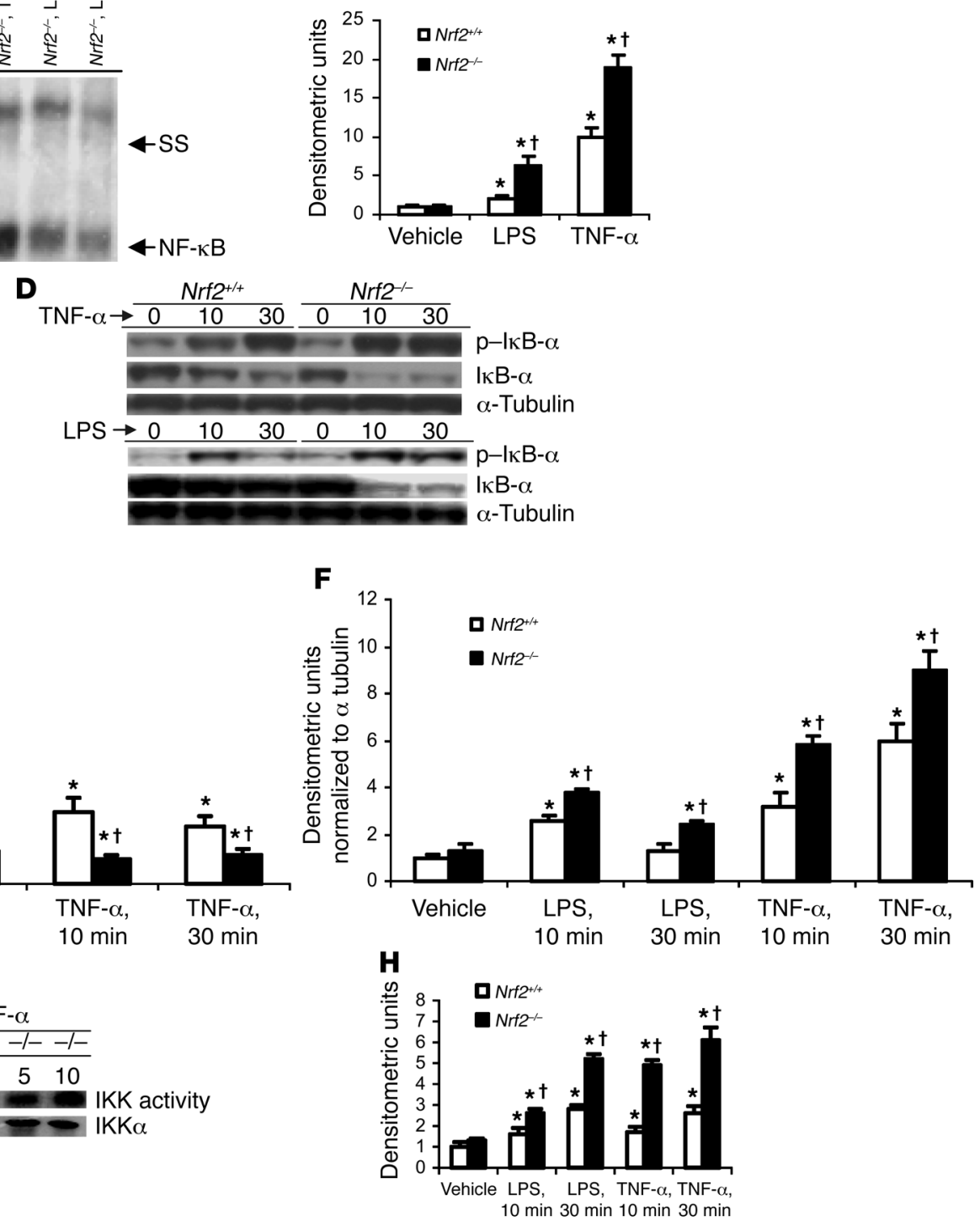

Figure 8

LPS and/or TNF- $\alpha$ stimulus induces greater NF-кB activation in Nrf2-deficient MEFs. (A) Nuclear extracts from Nrf2+/+ and Nrf2-/- MEFs were assayed for NF-kB DNA-binding activity by EMSA 30 minutes after LPS $(0.5 \mu \mathrm{g} / \mathrm{ml})$ and or TNF- $\alpha$ ( $10 \mathrm{ng} / \mathrm{ml})$. The major NF-kB bands contained p65 and p55 subunits, as determined by the supershift analysis using p65 and p55 antibody. (B) Quantification of NF-kB DNA-binding was performed by densitometric analysis. All values are mean \pm SEM $(n=3)$ and are represented relative to respective vehicle control. (C) NF- $\mathrm{KB}-\mathrm{mediated}$ reporter activity in MEFs of both genotypes challenged with LPS $(0.5 \mu \mathrm{g} / \mathrm{ml})$ and TNF- $\alpha$ (10 $\mathrm{ng} / \mathrm{ml})$. At 24 hours after transfection with $\mathrm{p}-\mathrm{NF}-\mathrm{kB}-\mathrm{LuC}$ vector, cells were treated with LPS and/or TNF- $\alpha$ for 3 hours, and then luciferase activity was measured. Data are mean \pm SEM from 3 independent experiments $(n=3)$ and are represented relative to respective vehicle control. (D) Immunoblot of IкB- $\alpha$ and $p-I \kappa B-\alpha$ protein in $N r f 2^{+/+}$

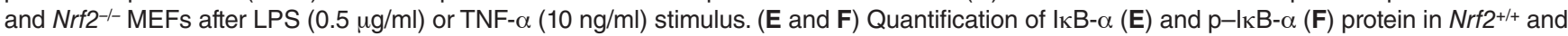
$\mathrm{Nrf2}^{-1-}$ MEFs by densitometric analysis. Data are mean \pm SEM $(n=3)$ and are shown as relative to respective vehicle control. (G) IKK activity in $\mathrm{Nrf2}^{+/+}$and $\mathrm{Nrf2}^{-/-}$MEFs after LPS $(0.5 \mu \mathrm{g} / \mathrm{ml})$ or TNF- $\alpha(10 \mathrm{ng} / \mathrm{ml})$ stimulus. (H) Quantification of IKK activity in $\mathrm{Nrf2}^{+/+}$and $\mathrm{Nrf2} 2^{-/-} \mathrm{MEFs}$ by densitometric analysis. Densitometric units are normalized to IKK $\alpha$. Data are mean $\pm \operatorname{SEM}(n=3)$ and are relative to respective controls. ${ }^{*}$ Differs from vehicle control of the same genotype. tDiffers from wild-type treatment group. $P<0.05$.

The ratio of GSH to oxidized GSH (GSSG) after LPS challenge was significantly higher in the lungs of wild-type mice, implying greater amounts of GSSG in $\mathrm{Nrf2}^{-1-}$ lungs and thus a difference in redox status between the 2 genotypes (Figure 10C).
$\mathrm{N}$-acetyl cysteine and GSH-monoethyl ester decrease LPS- and TNF- $\alpha-$ induced NF-KB activation in Nrf2-deficient MEFs. To investigate whether replenishing antioxidants could suppress the enhanced $\mathrm{NF}-\kappa \mathrm{B}$ activation observed in Nrf2 $2^{-/}$cells, MEFs transfected with 


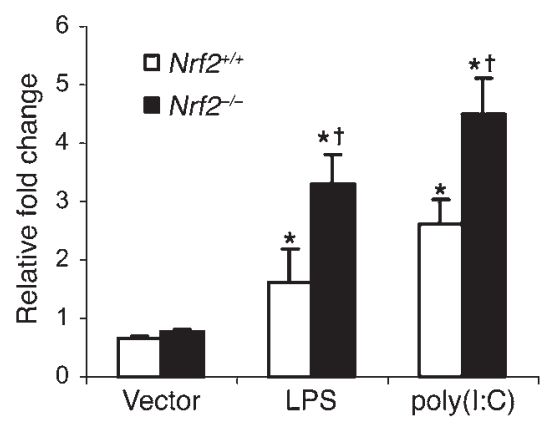

Figure 9

Nrf2 deficiency increases LPS- and or poly(I:C)-induced IRF3-mediated luciferase reporter activity in MEFs. At 24 hours after transfection with ISRE-Tk-Luc vector, cells were treated with LPS and or poly $(\mathrm{I}: C)$ for 6 hours, and luciferase assays were performed 6 hours after treatment. For poly(I:C) stimulation, MEFs were transfected with $6 \mu \mathrm{g}$ of poly $(\mathrm{I}: \mathrm{C})$ in $8 \mu \mathrm{l}$ of Lipofectamine2000. Data are mean \pm SEM from 3 independent experiments; $n=3$. ${ }^{*}$ Differs from vehicle control of the same genotype; †Differs from wild-type treatment group. $P<0.05$.

NF- $\kappa B-L u c$ reporter vector were pretreated with $\mathrm{N}$-acetyl cysteine (NAC) or GSH-monoethyl ester for 1 hour and then challenged with LPS or TNF- $\alpha$. Pretreatment with NAC or GSH-monoethyl ester significantly attenuated NF- $\mathrm{BB}$-mediated reporter activity in $\mathrm{Nrf2}^{-/}$cells elicited in response to LPS or TNF- $\alpha$ (Figure 11A).

NAC abrogates LPS-induced proinflammatory gene expression in the lungs of Nrf2-deficient mice and protects against lethality. Since LPS challenge enhanced the expression of several NF-кB-regulated proinflammatory genes in lungs of $\mathrm{Nrf2}^{-/-}$mice compared with wild-type littermates, we investigated whether administration of an exogenous antioxidant could attenuate this augmented proinflammatory cascade. Mice were pretreated with NAC (500 mg/kg body weight) and then challenged with nonlethal doses of LPS. After $30 \mathrm{~min}-$ utes of LPS challenge, selected proinflammatory genes were measured by real-time PCR analysis. Transcript levels of TNF- $\alpha, I L-1 \beta$, and $I L-6$ were significantly reduced in the lungs of $N r f 2^{-/}$mice by pretreatment with NAC (Figure 11B). Concordantly, the influx of inflammatory cells was also significantly reduced by pretreatment of $\mathrm{Nrf2}^{-{ }^{-}}$mice with NAC (Figure 11C). We next investigated to determine whether exogenous NAC supplementation could protect against LPS-induced septic shock in $\mathrm{Nrf2^{-/- }}$ mice. Mice of both genotypes were pretreated with NAC $(500 \mathrm{mg} / \mathrm{kg}$ body weight) for 4 days prior to LPS challenge (1.5 mg per mouse). All $\mathrm{Nrf2^{-/ }}$ mice pretreated with saline died within 56 hours while $40 \%$ of mice pretreated with NAC survived (Figure 11D). Pretreatment of wild-type mice with NAC provided modest protection. These results suggest that exogenous antioxidants such as NAC can partially ameliorate the phenotype of $\mathrm{Nrf2}^{-/-}$mice.

\section{Discussion}

Deciphering novel host factors that modulate the innate immune response during sepsis and septic shock not only improves our insight into this complex disease but also provides avenues for designing novel therapies that could minimize mortality. The present study showed Nrf2 to be a critical host factor for mounting an appropriate innate immune response, which determines survival during septic shock. Disruption of Nrf2 in mice caused greater sensitivity to septic shock induced by either LPS or CLP. $\mathrm{Nrf2}$ deficiency resulted in augmented lung inflammation in response to nonlethal challenge with LPS or TNF- $\alpha$. Systematic gene expression analyses by microarray and subsequent validation by real-time PCR demonstrated that the expression of effector genes (cytokines, chemokines, adhesion molecules, and receptors) of the innate immune response was dysregulated in $\mathrm{Nrf2^{-/ }}$ lungs in response to LPS. Nrf2 suppressed inflammation by inhibiting $\mathrm{NF}-\kappa \mathrm{B}$ activation through maintenance of redox status. Pharmacological repletion of cellular antioxidants by administering NAC partially protected $N r f 2^{-/-}$mice from LPS-induced lung inflammation and lethality, indicating the importance of $\mathrm{Nrf} 2$-mediated maintenance of antioxidants in counteracting septic shock. Collectively, the results of this study support a critical role for Nrf2 in mounting an appropriate innate immune response during sepsis.

Sepsis and septic shock by CLP or i.p. administration of a lethal dose of LPS induced greater mortality in Nrf2-disrupted compared with wild-type mice. During a gram-negative bacterial infection, LPS initiates the innate immune response through the TLR4 signaling pathway (23). Mice with either defective or disrupted TLR4 fail to respond to LPS and are more susceptible to bacteremia $(24,25)$. Conversely, aberrant expression of TLR4 enhances sensitivity to LPS (26). Microarray analysis demonstrated no change in the expression of TLR4 in the lungs, constitutively and after LPS challenge between the $\mathrm{Nrf2^{+/+ }}$ and $\mathrm{Nrf2^{-/- }}$ mice. Furthermore, there were no differences in constitutive expression of TLR 4 by immunoblot in peritoneal macrophages derived from $\mathrm{Nrf2}^{+/+}$and $\mathrm{Nrf2^{-/- }}$ mice (Supplemental Figure 2A). TNF- $\alpha$ is one of the early proinflammatory cytokines secreted during LPS/CLP-induced shock and is primarily secreted by macrophages and neutrophils (27-29). Lethal
A


B

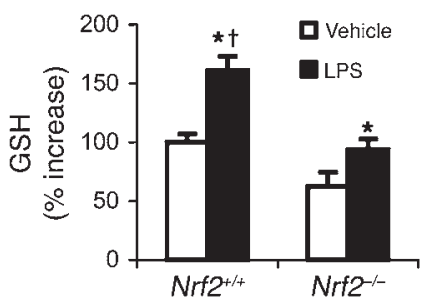

D

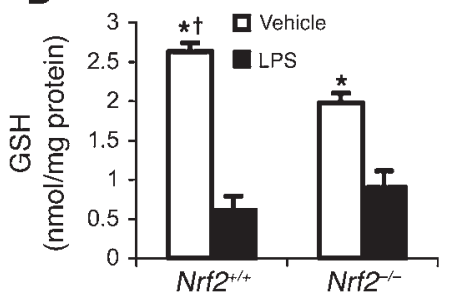

\section{Figure 10}

Lower levels of GSH in the lungs and MEFs of Nrf2-deficient mice. (A) Constitutive expression of GCLC in lungs and MEFs of $\mathrm{Nrf2}^{+/+}$and $\mathrm{Nrf2}^{-1-}$ mice. (B) GSH levels in the lungs of mice of both genotypes 24 hours after LPS instillation (10 $\mu \mathrm{g}$ per mouse). Data are mean \pm SEM from 3 independent experiments and are expressed as percentage increases relative to vehicle-treated $\mathrm{Nrf2}^{+/+}$group. (C) Ratio of GSH to GSSG measured 24 hours after LPS instillation in the lung of $\mathrm{Nrf2}^{+/+}$ and $\mathrm{Nrf2}^{-/-}$mice. Data are mean \pm SEM from 3 independent experiments. (D) GSH levels in $\mathrm{Nrf2}^{+/+}$and $\mathrm{Nrf2}^{-/-}$MEFs at 1 hour after LPS $(0.5 \mu \mathrm{g} / \mathrm{ml})$ or TNF- $\alpha(10 \mathrm{ng} / \mathrm{ml})$ stimulus. Data are presented as mean $\pm \mathrm{SEM} ; n=4$. *Differs from vehicle control of the same genotype. ${ }^{\dagger}$ Differs from wild-type treatment group. $P<0.05$. 
A

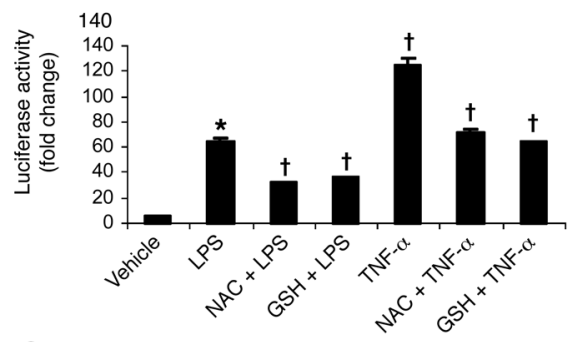

C

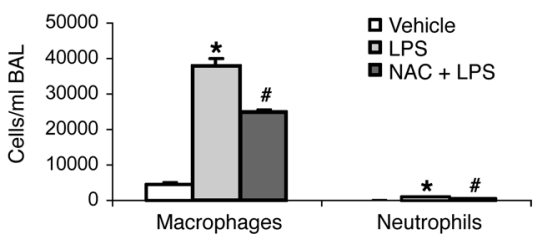

B

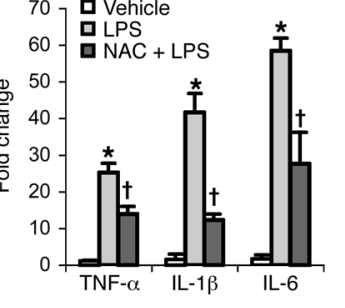

D

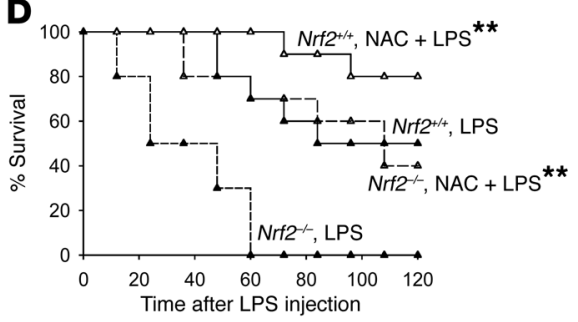

Figure 11

Pretreatment with exogenous antioxidants alleviates inflammation in Nrf2-deficient mice. (A) $\mathrm{NF}-\kappa_{\mathrm{B}}$-mediated luciferase reporter activity in Nrf2-- MEFs pretreated for 1 hour with NAC $(10 \mathrm{mM})$ and/or GSH-monoethyl ester $(\mathrm{GSH})(1 \mathrm{mM})$ after 3 hours of LPS $(0.5 \mu \mathrm{g} / \mathrm{ml})$ and/or TNF- $\alpha(10 \mathrm{ng} / \mathrm{ml})$ stimulus. Data are presented as mean \pm SEM $(n=4)$. *Differs from vehicle control. tDiffers from group that was treated with LPS or TNF- $\alpha$ only. $P<0.05$. (B) Expression of TNF- $\alpha$, IL- $1 \beta$, and IL- 6 by real-time PCR at 30 minutes in the lungs of $\mathrm{Nrf2}^{-/}$mice pretreated with NAC after LPS (i.p., $60 \mu \mathrm{g}$ per mouse) challenge. (C) BAL fluid analysis at 6 hours in lungs of $\mathrm{Nrf2}^{-/-}$mice pretreated with NAC after LPS (i.p., $60 \mu \mathrm{g}$ per mouse) challenge. $\mathrm{Nrf2}^{-/-}$mice were pretreated with 3 doses of NAC (500 mg/kg body weight, i.p., every 4 hours). Data are presented as mean \pm SEM. $n=4$. "Differs from only LPS treatment. $P<0.05$. (D) LPS-induced mortality in $\mathrm{Nrf2}^{-/-}$and $\mathrm{Nrf2+/+}$ mice pretreated with NAC. Age-matched male $\mathrm{Nrf2}^{-I_{-}}(n=10)$ and $\mathrm{Nrf}^{+/+}$mice $(n=10)$ were pretreated with NAC (i.p., $500 \mathrm{mg} / \mathrm{kg}$ body weight) and/or saline every day for 4 days followed by LPS challenge ( $1.5 \mathrm{mg}$ per mouse). Mortality was assessed every 12 hours for 5 days. ${ }^{* *}$ Mice pretreated with NAC had improved survival compared with vehicle-pretreated mice. $P<0.05$.

and nonlethal doses of LPS as well as CLP evoked higher levels of TNF- $\alpha$ in $\mathrm{Nrf2} 2^{-/-}$mice. Moreover, peritoneal macrophages isolated from $\mathrm{Nrf2^{-/- }}$ mice also showed significantly higher secretion of TNF- $\alpha$ in response to LPS. Taken together, these results suggest an early augmented inflammation in $\mathrm{Nrf2^{-/- }}$ mice compared with $\mathrm{Nrf2} 2^{+/+}$mice. To investigate whether TNF- $\alpha$ has any potential influence on the observed amplified inflammation in Nrf2-deficient lungs, $\mathrm{Nrf2} 2^{+/+}$and $\mathrm{Nrf2} 2^{-/-}$mice were treated with recombinant TNF- $\alpha$. TNF- $\alpha$ stimulus induced greater expression of proinflammatory genes ( $T N F-\alpha, I L-1 \beta$, and $I L-6)$ as well as inflammation demonstrated by BAL fluid analysis and histopathology in the lungs of $N r f 2^{-/-}$mice. These results indicate that TNF- $\alpha$ might partly contribute to LPS-induced enhanced inflammation in $\mathrm{Nrf2} 2^{-/-}$mice by autocrine action (30). In addition, these results also suggest that amplified inflammatory response observed in $\mathrm{Nrf2}^{-1-}$ mice is not limited to LPS-TLR signaling.

Global gene expression profiling demonstrated a complete dysregulation of several molecular components of the innate immune response regulated by both MyD88-dependent and -independent signaling at multiple time points in the lungs of $\mathrm{Nrf2}^{-/-}$mice after a nonlethal dose of LPS. Cytokines (IL-1 $\alpha, T N F-\alpha, I L-6, G M-C S F$, and $G-C S F)$, CXC chemokines (KC, MIP2, IP-10, ITAC, and MIG), CC chemokines (MIP-1 $\alpha, M C P-1, M C P 5$, and TARC), and cell adhesion molecules/receptors (CD-14, SELE, SELPL, VCAM1, TREM1) were among the main components of the innate immune response that were expressed at significantly higher levels in Nrf2-/- lungs when compared with wildtype littermates at 30 minutes after LPS challenge. CD14, the LPS-binding coreceptor that mediates LPS-TLR4 signaling, was induced to a greater extent in the lungs of $N r f 2^{-/-}$mice than in the wild-type mice in response to LPS; however, constitutively, there was no difference in the expression between the genotypes (Supplemental Figure 2B). Elevated expression of CD14 has been associated with increased inflammation; neutralization of CD14 with an antibody protected primates against lethal endotoxic shock and lung inflammation (31). Collectively, the temporal analysis (0, 30 minutes, 1 hour, 6 hours, and 24 hours) of gene expression suggests the following: (a) in general, Nrf2 deficiency induced dysregulated global expression of genes that encode molecular components of innate immunity (e.g., peptidoglycanrecognition proteins, proinflammatory cytokines, chemokines, and adhesion molecules and receptors); (b) the transcriptional dysregulation of effector molecules of innate immunity in $\mathrm{Nrf2^{-/- }}$ lungs was more prominent at early stages (30 minutes) of inflammation; (c) although the degree of expression of some of the inflammatory genes in wild-type lungs was either equal to or higher than that in $\mathrm{Nrf2^{-/- }}$ lungs at later stages of LPS stimulation, the greater lung pathologic damage in the $\mathrm{Nrf}^{-/-}$mice supports the conclusion that the enhanced expression of proinflammatory genes during the early stages (as early as 30 minutes) of LPS administration determines the degree of inflammatory insult. Taken together, these results suggest the critical role of Nrf2 in mounting an appropriate innate immune response by controlling an early surge of proinflammatory genes.

The innate immune response triggered by LPS-TLR4 signaling is primarily regulated by NF- $\mathrm{KB}(30)$. The expression of most of the LPSinduced proinflammatory genes that were upregulated to a greater

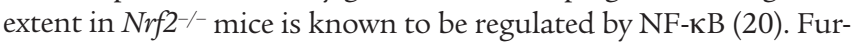
thermore, transcripts of several members of the NF- $\mathrm{KB}$ family (such as C-REL, RELB, NFKBIZ, NFKB2, and NFKBIE) were significantly higher in $N r f 2^{-/-}$lungs after LPS challenge. NF-кB activation analyzed by EMSA in lung, peritoneal macrophages, and MEFs of $\mathrm{Nrf2}^{-/-}$ mice was markedly higher after LPS stimulation as compared with wild-type. Further, NF-кB-mediated transcriptional reporter activity was greater in $\mathrm{Nrf2}^{---}$MEFs in response to LPS or TNF- $\alpha$. NF-кB cytosolic inhibitor IкB- $\alpha$ showed increased degradation and phosphorylation in $\mathrm{Nrf2}^{-/-}$cells after LPS or TNF- $\alpha$ challenge. Phosphorylation of IKB- $\alpha$ is mediated by IKK, leading to ubiquitination and degradation of IKB- $\alpha$. Analysis of IKK kinase activity in $\mathrm{Nrf2^{-/- }}$ and $\mathrm{Nrf2}^{+/+} \mathrm{MEF}$ in response to LPS or TNF- $\alpha$ demonstrated increased activity in the former group. Thus, $\mathrm{Nrf} 2$ regulates $\mathrm{NF}-\kappa \mathrm{B}$ activation largely by modulating its upstream signaling components. 
LPS activates NF- $\kappa$ B and IRF3 via MyD88-dependent and -independent signaling, respectively $(21,30)$. Activation of IRF3 leads to expression of interferon and interferon inducible genes through activation of TANK-binding kinase and IKKE (32). Global gene expression analysis by microarray revealed a subset of genes (IP-10, MIG, ITAC, and ISG54; Supplemental Table 9) regulated specifically by IRF3 signaling pathway (33) that were upregulated to higher levels in Nrf2 $2^{-/}$mice. To determine whether Nrf2 affects both MyD88-dependent and -independent signaling, an IRF3-mediated luciferase reporter assay was performed. In response to poly(I:C) stimulation, which specifically elicits inflammatory response via MyD88-indpendent pathways, the IRF3-mediated luciferase reporter activity was significantly higher in $\mathrm{Nrf2} 2^{-/-}$cells. Similarly, in response to LPS, the IRF3 reporter activity was elevated in $\mathrm{Nrf2^{-/ }}$ compared with $\mathrm{Nrf2}^{+/+} \mathrm{MEFs}$. These results indicate that $\mathrm{Nrf} 2$ may affect both MyD88-dependent and -independent signaling.

Although it is not clear how Nrf2 interferes with LPS signaling to inhibit NF- $\kappa B$, several lines of evidence indicate that the redox status of the cells modulates LPS-induced NF- $\kappa$ B activation (34-37). LPS stimulation led to higher expression of genes involved in the production of superoxide (NCF1 and NCF4) and nitric oxide (iNOS) in Nrf2 $2^{-/}$lungs. Cellular antioxidant defenses can counter inflammation by limiting ROS levels. Levels of GSH and the transcript of the rate-limiting gene involved in its synthesis, GCLC, were significantly higher in lungs and MEFs of wild-type mice than of $\mathrm{Nrf2}^{-/-}$mice. Lower levels of GSH have been reported to augment NF- $\kappa \mathrm{B}$ activation in response to LPS stimulation (38). Basal expression of several antioxidative enzymes, including glutathione reductase 1, thioredoxin reductase, and GPX2, were higher in lungs of $\mathrm{Nrf2}^{+/+}$mice compared with $\mathrm{Nrf2}^{-/-}$. Enhanced activation of NF-KB as early as 30 minutes in the lungs and MEFs and 20 minutes in peritoneal macrophages after LPS challenge of $\mathrm{Nrf2}^{-/-}$mice underscores the positive influence of constitutive antioxidants in modulating the ensuing inflammatory cascade. Further, pretreatment of $\mathrm{Nrf2}^{-{ }^{--}}$MEFs with antioxidants such as NAC and GSH monoethyl ester greatly suppressed NF- $\mathrm{BB}$ activation in response to LPS or TNF- $\alpha$. These results suggest that Nrf2-mediated maintenance of cellular redox status through regulation of GSH and perhaps other cellular antioxidants is crucial for regulating NF-кB activation. During the course of LPS-induced inflammation, expression levels of many antioxidative genes were significantly lower in the lungs of knockout mice compared with wild-type mice (Supplemental Table 7). Among these antioxidative enzymes, expression of GPX2 was highest in lungs of $\mathrm{Nrf2}^{+/+}$mice. A previous study showed that GPX2 is the only inducible form of GSH peroxidase in the lungs that is regulated by $\mathrm{Nrf2}$ (7). A protective role of GSH peroxidase in LPS-induced inflammation has been previously reported (39). These results indicate that Nrf2-directed constitutive regulation of cellular redox status is fundamental in determining the outcome of the innate immune response. In corroboration with in vitro experiments, pretreatment of $\mathrm{Nrf2}^{-/-}$mice with NAC greatly diminished LPS-induced proinflammatory gene expression as well as inflammation in lungs. In addition, NAC pretreatment significantly reduced the LPS-induced septic mortality in $\mathrm{Nrf2^{-/- }}$ mice while moderate protection was conferred in wild-type littermates. Altogether, these results imply that maintenance of redox equilibrium by regulating GSH and other antioxidant enzymes through Nrf2 may be partially responsible for alleviating LPSinduced inflammation.
The results of the current study suggest that $\mathrm{Nrf} 2$ regulates the innate immune response during sepsis and improves survival by maintaining redox homeostasis and restraint of the dysregulation of proinflammatory signaling pathways (MyD88-dependent and -independent and TNF- $\alpha$ signaling). A recent report by Suh et al. (40) showed that aged rats have reduced levels of GSH and diminished expression of GSH-biosynthetic enzymes (GCLC and glutamate cysteine ligase, modifier subunit [GCLM]) as a result of a decline in the transcriptional activity of Nrf2. Thus, it will be worth investigating whether variation in the Nrf2 signaling pathway mediates the increased susceptibility and severity of inflammation and septic shock in elderly patients. In addition, correction of low Nrf2-mediated transcriptional activity through the use of pharmacological activators of $\mathrm{Nrf} 2$ signaling may be a novel therapeutic strategy for counteracting inflammation during sepsis.

\section{Methods}

Mice. Nrf2-deficient mice (CD-1 [Institute for Cancer Research]; $\mathrm{Nrf2}^{-{ }^{--}}$) were generated as described (41). Wild-type (CD-1 [Institute for Cancer Research]; $\left.\mathrm{Nrf}^{+/+}\right)$and $\mathrm{Nrf2}^{-/-}$mice were fed an AIN-76A diet and water ad libitum and were housed under controlled conditions $\left(25 \pm 2^{\circ} \mathrm{C}\right.$; 12 -hour light-dark periods). All experimental protocols conducted on the mice were performed in accordance with NIH guidelines and were approved by the Johns Hopkins University Animal Care and Use Committee.

Treatment. Endotoxic shock was induced in male mice (8 weeks old) of both genotypes by i.p. injection of LPS at doses of 0.75 or $1.5 \mathrm{mg}$ per mouse (Escherichia coli, serotype 055.B5; Sigma-Aldrich) as described (42). After LPS injection, the mice were monitored for 5 days. To induce nonlethal systemic inflammation, the mice were injected with LPS (i.p., $60 \mu \mathrm{g} /$ mouse) and or recombinant hTNF- $\alpha$ (i.p., $10 \mu \mathrm{g} /$ mouse) (R\&D Systems). Control mice received an equivalent volume of vehicle. Intratracheal LPS instillation was used for induction of local inflammation in the lungs. Mice were first anesthetized by i.p. injection with $0.1 \mathrm{ml}$ of a mixture of ketamine $(10 \mathrm{mg} / \mathrm{ml})$ and xylazine $(1 \mathrm{mg} / \mathrm{ml})$ in PBS. LPS was instilled intratracheally $(10 \mu \mathrm{g}$ in $50 \mu \mathrm{l}$ sterile PBS) during inspiration. Control mice received an equivalent volume of vehicle.

CLP. Polymicrobial sepsis was induced by CLP. Briefly, a midline laparotomy was performed on the anesthetized mice, and the cecum was identified. The distal $50 \%$ of exposed cecum was ligated with 3-0 silk suture and punctured with 1 pass of an 18-gauge needle. The cecum was replaced in the abdomen, and the incision was closed with 3-0 suture. Another set of mice was subjected to midline laparotomy and manipulation of cecum without ligation and puncture (sham operation). Postoperatively, the animals were resuscitated with $1 \mathrm{ml}$ subcutaneous injection of sterile $0.9 \% \mathrm{NaCl}$. Mice were monitored regularly, and survival was recorded over a period of 5 days.

$B A L$ and phenotyping. Mice were anesthetized with an overdose of sodium pentobarbital. The lungs were aspirated 3 times with $1 \mathrm{ml}$ of sterile PBS to collect BAL fluid. Cells were counted by using a hemocytometer, and differential cell counts were performed on 300 cells from BAL fluid with Wright-Giemsa stain (Baxter).

Histopathology and immunohistochemistry. Lungs were inflated with $10 \%$ buffered formalin through the trachea 24 hours after the treatment and subsequently fixed for 24 hours at $4^{\circ} \mathrm{C}$. After paraffin embedding, $5-\mu \mathrm{m} \mathrm{sec}$ tions were cut and stained with $\mathrm{H} \& \mathrm{E}$. For identification of neutrophils, lung sections were stained by using rat IgG anti-mouse neutrophil monoclonal antibody (Serotec) followed by the secondary goat anti-rat IgG conjugated to horseradish peroxidase. Color development was performed with $3^{\prime}, 3^{\prime}$ diaminobenzidine, and the slides were counterstained with hematoxylin. 
Measurement of myeloperoxidase. The activity of myeloperoxidase, an indicator of neutrophil accumulation, was measured in the supernatant fluid obtained from whole-lung homogenates as described (43).

Measurement of lung edema. Five animals per group were treated with LPS for 24 hours. Mice were sacrificed by i.p. injection of sodium pentobarbital, and the lungs were excised. All extrapulmonary tissue was cleared, weighed (wet weight), dried for 48 hours at $60^{\circ} \mathrm{C}$, and then weighed again (dry weight). Lung edema was expressed as the ratio of wet weight to dry weight.

ELISA. Levels of TNF- $\alpha$, TNFRI (p55), and TNFRII (p75) were measured by enzyme immunoassays by using murine ELISA kits (R\&D Systems).

Microarray. Mice of both genotypes were subjected to systemic inflammation by i.p. injection of LPS ( $60 \mu \mathrm{g}$ per mouse). Lungs were isolated at 30 minutes, 1 hour, 6 hours, 12 hours, and 24 hours after LPS challenge. Total RNA from the lungs was extracted by using TRIZOL reagent (Invitrogen Corp.). The isolated RNA was applied to Murine Genome MOE $430 \mathrm{~A}$ GeneChip arrays (Affymetrix) according to procedures described previously (5). This array contains probes for detecting approximately 14,500 well-characterized genes and 4371 expressed sequence tags.

Scanned output files were analyzed by using Affymetrix GeneChip Operating Software version 1.3 and were independently normalized to an average intensity of 500. Further analyses were done as described previously (5), by performing 9 pairwise comparisons for each group $\left(\mathrm{Nrf2}^{+/+}\right.$, LPS, $n=3$, versus $N r f 2^{+/+}$, vehicle, $n=3$, and $N r f 2^{-/-}$, LPS, $n=3$, versus $N r f 2^{--}$, vehicle, $n=3$ ). To limit the number of false positives, only those altered genes that showed a change of more than 1.5 fold and appeared in at least 6 of the 9 comparisons were selected. In addition, the MannWhitney pairwise comparison test was performed to rank the results by concordance as an indication of the significance $(P \leq 0.05)$ of each identified change in gene expression.

Real-time quantitative PCR. Total RNA was isolated by using TRIZOL reagent (Invitrogen Corp.), and reverse transcription was performed by using random hexamers and MultiScribe reverse transcriptase according to the manufacturer's recommendations (Applied Biosystems). Quantitative PCR analyses of selected genes were performed by using primers and probe sets commercially available from Applied Biosystems. Assays were performed by using the ABI 7000 Taqman system (Applied Biosystems). GAPDH was used for normalization.

Isolation of resident peritoneal macrophages and treatment. Resident peritoneal macrophages were harvested from 4 mice of each genotype by peritoneal lavage with $5 \mathrm{ml}$ of cold RPMI-1640 medium supplemented with $10 \%$ FBS. Isolated peritoneal macrophages from all mice of the same genotype were pooled and plated into 24 -well plates at a density of $1 \times 10^{6}$ cells $/ \mathrm{ml}$. Adherent cells were maintained in RPMI 1640 medium supplemented with $10 \% \mathrm{FBS}, 1 \%$ penicillin, and $1 \%$ streptomycin for 16 hours at $37^{\circ} \mathrm{C}$ in a $\mathrm{CO}_{2}$ incubator. Cells were then stimulated with LPS $(1 \mathrm{ng} / \mathrm{ml})$ in serum-free medium.

Electrophoretic mobility shift assay. Nuclear proteins were isolated from tissue or cells by using the protocol described previously (7). The NF- $\mathrm{KB}$ probe (5'-GTTGAGGGGACTTTCCCAGGC-3') (Promega) was end-labeled by $\mathrm{T} 4$ polynucleotide kinase in the presence of [ $\left.{ }^{32} \mathrm{P}\right]$ ATP $\gamma$. For EMSA, $5 \mu \mathrm{g}$ of nuclear proteins was incubated with the labeled NF-кB probe in the presence of poly (dI-dC) in binding buffer (Promega) at $4{ }^{\circ} \mathrm{C}$ for 20 minutes. The mixture was then resolved by electrophoresis on a $5 \%$ nondenaturing polyacrylamide gel and developed by autoradiography. For supershift analysis, nuclear proteins were incubated with 1 to $2 \mu \mathrm{g}$ of polyclonal antibody to either p65 and or p50 subunit of NF-אB (Santa Cruz Biotechnology Inc.) for 30 minutes after incubation with the labeled probe.

P65/RelA DNA-binding activity. DNA-binding activity of the p65/RelA

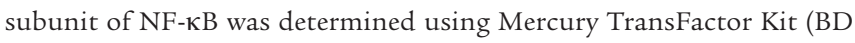
Biosciences). An equal amount of nuclear extracts was added to incubation wells precoated with the DNA-binding consensus sequence. The presence of translocated p65/RelA subunit was then assessed by using the Mercury TransFactor kit according to manufacturer instructions. Plates were read at $655 \mathrm{~nm}$, and results were expressed as OD.

Western blot analysis. Western blot analysis was performed according to previously published procedures (7), using antibodies specific for $\mathrm{p} 65, \mathrm{p} 50$, IкB- $\alpha, \alpha$-tubulin (Santa Cruz Biotechnology Inc.), p-ІкB- $\alpha$ (Cell Signaling Technology), TLR4, and CD14 (eBioscience).

In vitro IKK kinase activity. Cytoplasmic extracts were isolated from cells using cell lysis buffer (Cell Signaling Technology), and protein was measured by BCA protein assay kit (Pierce Biotechnology). Cytoplasmic extracts $(250 \mu \mathrm{g})$ were incubated with $1 \mu \mathrm{g}$ IKK $\alpha$ monoclonal antibody (Santa Cruz Biotechnology Inc.) for 2 hours at $4^{\circ} \mathrm{C}$, and then with protein $\mathrm{A} / \mathrm{G}$-conjugated Sepharose beads (Pierce Biotechnology) for 2 hours at $4^{\circ} \mathrm{C}$. After washing with cell lysis buffer 5 times and 1 time with the kinase buffer (Cell Signaling Technology), the beads were incubated with $20 \mu$ l kinase buffer containing $20 \mu \mathrm{M}$ adenosine 5 '-triphosphate (ATP), $5 \mu \mathrm{Ci}\left[{ }^{32} \mathrm{P}\right] \mathrm{ATP}$, and $1 \mu$ g glutathione $S$-transferase-IкB $\alpha$ (1-317) substrate (Santa Cruz Biotechnology Inc.) at $30^{\circ} \mathrm{C}$ for 30 minutes. The reaction was terminated by boiling the reaction mixture in $\times 5$ SDS sample buffer. Proteins were resolved on a $10 \%$ polyacrylamide gel under reducing conditions; the gel was dried, and the radiolabeled bands were visualized using autoradiography. To determine the total amounts of IKK in each sample, immunoblotting was performed. Proteins ( $30 \mathrm{~g}$ ) from whole-cell extract were resolved on a $12 \%$ SDS-acrylamide gel then electrotransferred to a polyvinylidene difluoride and probed for IKK $\alpha$ (Santa Cruz Biotechnology Inc.).

Transfection and luciferase assay. MEFs from mice of both genotypes were prepared from 13.5-day embryos as described (44) and grown in Iscove's modified Dulbecco's medium supplemented with $10 \%$ FBS, $0.5 \%$ penicillin, and $0.5 \%$ streptomycin. MEFs (60-80\% confluence) were transfected with luciferase reporter genes ( $\mathrm{p}-\mathrm{NF}-\mathrm{\kappa B}-\mathrm{Luc}$ or ISRE-Tk-Luc vector) by using Lipofectamine2000 (Invitrogen Corp.). The Renilla-luciferase reporter gene ( $\mathrm{p}-\mathrm{RL}-\mathrm{TK})$ was cotransfected for normalization. After the treatments, the reporter gene activity was measured using the Dual Luciferase Assay System (Promega). All transfection experiments were carried out in triplicate wells and were repeated separately at least 3 times.

Reduced and oxidized GSH. A Bioxytech GSH/GSSG-412 kit (Oxis International Inc.) was used to measure reduced GSH and GSSG in the lungs. Briefly, lung tissue was homogenized in cold $5 \%$ metaphosphoric acid. For measuring GSSG, 2-methyl-2-vinyl-pyridinium trifluoromethane sulfonate, a scavenger of reduced GSH, was added to an aliquot of lung homogenate. The homogenates were centrifuged at $5000 \mathrm{~g}$ for 5 minutes at $4{ }^{\circ} \mathrm{C}$, and the supernatant fluid was used to measure GSH and GSSG per the manufacturer's instructions. Total GSH in MEFs was measured as previously described (45).

Intervention with NAC. To investigate the effect of replenishing antioxidant in $\mathrm{Nrf}^{-1-}$ mice on lung inflammation induced by nonlethal dose of LPS (60 $\mu$ g per mouse), mice were pretreated with NAC (Sigma-Aldrich) (500 mg/kg body weight) 3 times, 4 hours apart. One hour after the last dose of NAC, LPS was injected and BAL fluid analysis and expression of inflammatory genes were performed as described above. To determine the effect of replenishing antioxidant in $\mathrm{Nrf2}^{-/-}$mice on LPS-induced septic shock, NAC ( $500 \mathrm{mg} / \mathrm{kg}$ body weight) was administered (i.p.) every day for 4 days. One hour after the last dose of NAC, a lethal dose of LPS (1.5 mg per mouse) was injected. Mortality was observed as described above.

Statistics. Data are expressed as mean \pm SEM. Student's 2-tailed $t$ test was used to evaluate the differences between the control and treatment groups within a single genotype as well as between genotypes. Survival studies were analyzed by using the log rank test. Statistical significance was accepted at $P<0.05$. 


\section{Acknowledgments}

We thank Mollie Meffert, Joel Pomerantz, and Antonio De Maio for helpful discussion. We thank Delisa Fairweather for critical reading of the manuscript. We are grateful to Dhan Kalvakolanu for ISRE-TK-Luc vector. This work was supported by NIH grants HL081205 (S. Biswal), CA94076 (T.W. Kensler), P50 HL073994 (S.P. Reddy), and P50 CA058184, National Institute of Environmental Health Sciences Center grant P30 ES 038819, the Young Clinical Scientist award from the Flight Attendant Research Institute (S. Biswal), and the Maryland Cigarette Restitution Fund (S. Biswal). R.K. Thimmulappa is a recipient of a Postdoctoral
Grant Award from the American Institute for Cancer Research. We acknowledge the help of Malu Mooley, Brian Schofield, and Judith Coram in our studies.

Received for publication May 31, 2005, and accepted in revised form January 31, 2006.

Address correspondence to: Shyam Biswal, Bloomberg School of Public Health, Johns Hopkins University, E7624, 615 North Wolfe Street, Baltimore, Maryland 21205, USA. Phone: (410) 955-4728; Fax: (410) 955-0116; E-mail: sbiswal@jhsph.edu.
1. Cohen, J. 2002. The immunopathogenesis of sepsis. Nature. 420:885-891.

2. Pinsky, M.R. 2004. Dysregulation of the immune response in severe sepsis. Am. J. Med. Sci. 328:220-229.

3. Angus, D.C., et al. 2001. Epidemiology of severe sepsis in the United States: analysis of incidence, outcome, and associated costs of care. Crit. Care Med. 29:1303-1310.

4. Arcaroli, J., Fessler, M.B., and Abraham, E. 2005. Genetic polymorphisms and sepsis. Shock. 24:300-312.

5. Thimmulappa, R.K., et al. 2002. Identification of Nrf2-regulated genes induced by the chemopreventive agent sulforaphane by oligonucleotide microarray. Cancer Res. 62:5196-5203.

6. Kwak, M.K., et al. 2003. Modulation of gene expression by cancer chemopreventive dithiolethiones through the Keap1-Nrf2 pathway. Identification of novel gene clusters for cell survival. J. Biol. Chem. 278:8135-8145.

7. Rangasamy, T., et al. 2004. Genetic ablation of Nrf2 enhances susceptibility to cigarette smoke-induced emphysema in mice. J. Clin. Invest. 114:1248-1259. doi:10.1172/JCI200421146.

8. Motohashi, H., and Yamamoto, M. 2004. Nrf2Keap1 defines a physiologically important stress response mechanism. Trends Mol. Med. 10:549-557.

9. Jain, A.K., Bloom, D.A., and Jaiswal, A.K. 2005. Nuclear import and export signals in control of NRF2. J. Biol. Chem. 280:29158-29168.

10. Velichkova, M., and Hasson, T. 2005. Keap1 regulates the oxidation-sensitive shuttling of Nrf2 into and out of the nucleus via a Crm1-dependent nuclear export mechanism. Mol. Cell. Biol. 25:4501-4513.

11. Ramos-Gomez, M., et al. 2001. Sensitivity to carcinogenesis is increased and chemoprotective efficacy of enzyme inducers is lost in Nrf2 transcription factor-deficient mice. Proc. Natl. Acad. Sci. U. S. A. 98:3410-3415.

12. Rangasamy, T., et al. 2005. Disruption of Nrf2 enhances susceptibility to severe airway inflammation and asthma in mice. J. Exp. Med. 202:47-59.

13. Chignard, M., and Balloy, V. 2000. Neutrophil recruitment and increased permeability during acute lung injury induced by lipopolysaccharide. Am. J. Physiol. Lung Cell. Mol. Physiol. 279:L1083-L1090.

14. Eskandari, M.K., et al. 1992. Anti-tumor necrosis factor antibody therapy fails to prevent lethality after cecal ligation and puncture or endotoxemia. J. Immunol. 148:2724-2730.

15. Dziarski, R., Platt, K.A., Gelius, E., Steiner, H., and Gupta, D. 2003. Defect in neutrophil killing and increased susceptibility to infection with nonpathogenic gram-positive bacteria in peptidoglycan recognition protein-S (PGRP-S)-deficient mice. Blood. 102:689-697.
16. Riedemann, N.C., et al. 2002. Increased C5a receptor expression in sepsis. J. Clin. Invest. 110:101-108. doi:10.1172/JCI200421146.

17. Mori, M., and Gotoh, T. 2004. Arginine metabolic enzymes, nitric oxide and infection. J. Nutr. 134:2820S-2825S; discussion 2853S.

18. Terness, P., et al. 2002. Inhibition of allogeneic T cell proliferation by indoleamine 2,3-dioxygenase-expressing dendritic cells: mediation of suppression by tryptophan metabolites. J. Exp. Med. 196:447-457.

19. Brumell, J.H., et al. 1999. Expression of the protein kinase $\mathrm{C}$ substrate pleckstrin in macrophages: association with phagosomal membranes. J. Immunol. 163:3388-3395.

20. Blackwell, T.S., and Christman, J.W. 1997. The role of nuclear factor-kappa B in cytokine gene regulation. Am. J. Respir. Cell Mol. Biol. 17:3-9.

21. Doyle, S., et al. 2002. IRF3 mediates a TLR3/ TLR4-specific antiviral gene program. Immunity. 17:251-263

22. Yamamoto, M., et al. 2003. Role of adaptor TRIF in the MyD88-independent toll-like receptor signaling pathway. Science. 301:640-643.

23. Akira, S., and Takeda, K. 2004. Toll-like receptor signalling. Nat. Rev. Immunol. 4:499-511.

24. Hoshino, K., et al. 1999. Cutting edge: Toll-like receptor 4 (TLR4)-deficient mice are hyporesponsive to lipopolysaccharide: evidence for TLR4 as the Lps gene product. J. Immunol. 162:3749-3752.

25. Poltorak, A., et al. 1998. Defective LPS signaling in $\mathrm{C} 3 \mathrm{H} / \mathrm{HeJ}$ and $\mathrm{C} 57 \mathrm{BL} / 10 \mathrm{ScCr}$ mice: mutations in Tlr4 gene. Science. 282:2085-2088.

26. McCartney-Francis, N., Jin, W., and Wahl, S.M. 2004. Aberrant Toll receptor expression and endotoxin hypersensitivity in mice lacking a functional TGF-beta 1 signaling pathway. J. Immunol. 172:3814-3821.

27. Grivennikov, S.I., et al. 2005. Distinct and nonredundant in vivo functions of TNF produced by $t$ cells and macrophages/neutrophils: protective and deleterious effects. Immunity. 22:93-104.

28. Mathison, J.C., Wolfson, E., and Ulevitch, R.J. 1988. Participation of tumor necrosis factor in the mediation of gram negative bacterial lipopolysaccharide-induced injury in rabbits. J. Clin. Invest. 81:1925-1937.

29. Beutler, B., Milsark, I.W., and Cerami, A.C. 1985. Passive immunization against cachectin/tumor necrosis factor protects mice from lethal effect of endotoxin. Science. 229:869-871.

30. Covert, M.W., Leung, T.H., Gaston, J.E., and Baltimore, D. 2005. Achieving stability of lipopolysaccharide-induced NF-kappaB activation. Science. 309:1854-1857

31. Leturcq, D.J., et al. 1996. Antibodies against CD14 protect primates from endotoxin-induced shock. J. Clin. Invest. 98:1533-1538.

32. Fitzgerald, K.A., et al. 2003. IKKepsilon and TBK1 are essential components of the IRF3 signaling pathway. Nat. Immunol. 4:491-496.

33. Hemmi, H., et al. 2004. The roles of two IkappaB kinase-related kinases in lipopolysaccharide and double stranded RNA signaling and viral infection. J. Exp. Med. 199:1641-1650.

34. Janssen-Heininger, Y.M., Poynter, M.E., and Baeuerle, P.A. 2000. Recent advances towards understanding redox mechanisms in the activation of nuclear factor kappaB. Free Radic. Biol. Med. 28:1317-1327.

35. Asehnoune, K., Strassheim, D., Mitra, S., Kim, J.Y., and Abraham, E. 2004. Involvement of reactive oxygen species in toll-like receptor 4-dependent activation of NF-kappaB. J. Immunol. 172:2522-2529.

36. Sanlioglu, S., et al. 2001. Lipopolysaccharide induces Rac1-dependent reactive oxygen species formation and coordinates tumor necrosis factor-alpha secretion through IKK regulation of NF-kappa B. J. Biol. Chem. 276:30188-30198.

37. Asehnoune, K., Strassheim, D., Mitra, S., Kim, J.Y., and Abraham, E. 2004. Involvement of reactive oxygen species in Toll-like receptor 4-dependent activation of NF-kappa B. J. Immunol. 172:2522-2529.

38. Ardite, E., Barbera,J.A., Roca, J., and Fernandez-Checa, J.C. 2004. Glutathione depletion impairs myogenic differentiation of murine skeletal muscle C2C12 cells through sustained NF-kappaB activation. Am. J. Pathol. 165:719-728.

39. Mirochnitchenko, O., et al. 2000. Endotoxemia in transgenic mice overexpressing human glutathione peroxidases. Circ. Res. 87:289-295.

40. Suh, J.H., et al. 2004. Decline in transcriptional activity of $\mathrm{Nrf} 2$ causes age-related loss of glutathione synthesis, which is reversible with lipoic acid. Proc. Natl. Acad. Sci. U. S. A. 101:3381-3386.

41. Itoh, K., et al. 1997. An Nrf2/small Maf heterodimer mediates the induction of phase II detoxifying enzyme genes through antioxidant response elements. Biochem. Biophys. Res. Commun. 236:313-322.

42. Zisman, D.A., et al. 1997. MCP-1 protects mice in lethal endotoxemia. J. Clin. Invest. 99:2832-2836.

43. Speyer, C.L., et al. 2003. Regulatory effects of iNOS on acute lung inflammatory responses in mice. Am. J. Pathol. 163:2319-2328.

44. Sasaki, H., et al. 2002. Electrophile response element-mediated induction of the cystine/glutamate exchange transporter gene expression. J. Biol. Chem. 277:44765-44771.

45. Tirumalai, R., Rajesh Kumar, T., Mai, K.H., and Biswal, S. 2002. Acrolein causes transcriptional induction of phase II genes by activation of Nrf2 in human lung type II epithelial (A549) cells. Toxicol. Lett. 132:27-36. 